J.Y. Dupuis MD, R. Martin MD FRCP,

J.M. Tessonnier MD, J.P. Tétrault JP MD FRCP

\title{
Clinical assessment of the muscular response to tetanic nerve stimulation
}

Tetanic stimulation has been used for many years to detect

The study was undertaken in order to determine clinical tactile evaluation of tetanic nerve stimulation $(50 \mathrm{~Hz}, 5 \mathrm{sec}$ ) as a means of detecting fade and possible residual curarization. Forty-four patients were studied and 128 clinical evaluations by eight different observers were performed at various levels of neuromuscular blockade. Tetanic fade was detected reliably by clinical evaluation only when high degrees of fade (letanic fade ratio of 0.3 or less) were detected with a force-displacement transducer. We conclude that the clinical tactile assessment of the response to tetanic stimulation is not accurate except at very high degrees of fade and that its usefulness in monitoring neuromuscular recovery is doubtful.

La présente étude avait pour but de justifier l'évaluation tactile clinique de la réponse à la stimulation tétanique $(50 \mathrm{~Hz}, 5 \mathrm{sec}$ ) comme moyen de détection d' un affaiblissement à cette stimulation télanique el d'une curarisation résiduelle possible. Quarantequatre patients ont été étudiés et soumis a 128 évaluations cliniques de l'affaiblissement à la stimulation tétanique par huit observateurs différents, et ce à divers niveaux de bloc neuromusculaire. L'affaiblissement tétanique n'a été détecté par l'évaluation clinique que lorsque de hauts niveaux d' affaiblissement étaient objectivés au transducteur de force (rapport d'affaiblissement tétanique de 0,3 ou moins). Nous concluons que l'évaluation clinique tactile de la réponse à la stimulation tétanique n'est pas un moyen efficace de détection de l'affaiblis. sement téranique et que son utilité comme moyen de monitorage de la récupération neuromusculaire peut être mise en doute.

From the Department of Anaesthesia, University of Sherbrooke, Sherbrooke, Quebec, Canada.

Address correspondence 10: Dr. R. Martin, Department of Anaesthesia, Centre Hospitalier Universitaire de Sherbrooke, 3001, 12th Avenue North, Fleurimont (Quebec), JIH 5N4. the residual effect of nondepolarizing muscle relaxants. ${ }^{1-3}$ Although the use of high-frequency stimulation is limited because of pain and post-tetanic facilitation, the current belief is that clinical tactile evaluation of the response to tetanic nerve stimulation $(50 \mathrm{~Hz}$ for $5 \mathrm{sec}$ ) is the most sensitive tool to detect residual curarization, in the absence of electromyographic (EMG) or electromechanic (MMG) monitoring. ${ }^{4-6}$ As this has never been supported by controlled trial, we undertook the present study to determine the value of clinical tactile evaluation of tetanic nerve stimulation $(50 \mathrm{~Hz}$ for $5 \mathrm{sec}$ ), as a means of detecting fade and possible residual curarization.

\section{Methods}

The protocol was approved by the Hospital, and University's Ethics Committee and 44 adult patients, ASA physical status I to III and without neuromuscular disease, gave written consent to participate in the study. All patients had a similar type of anaesthesic. After premedication with diazepam $0.15 \mathrm{mg} \cdot \mathrm{kg}^{-1}$ or lorazepam 0.03 $\mathrm{mg} \cdot \mathrm{kg}^{-1}$, anaesthesia was induced with thiopentone 3 to $5 \mathrm{mg} \cdot \mathrm{kg}^{-1}$ and fentanyl $\left(1-3 \mu \mathrm{g} \cdot \mathrm{kg}^{-1}\right)$ or sufentanil $\left(0.25-0.5 \mu \mathrm{g} \cdot \mathrm{kg}^{-1}\right)$ as required to maintain cardiovascular stability. Tracheal intubation was then performed after administration of a bolus of vecuronium of 0.06 to 0.08 $\mathrm{mg} \cdot \mathrm{kg}^{-1}$. Anaesthesia was maintained with isoflurane one per cent in a mixture of oxygen 40 per cent and nitrous oxide 60 per cent. Supplements of vecuronium and intravenous narcotics were added when necessary.

Following induction of anaesthesia, both ulnar nerves were simultaneously stimulated at the wrist, through cutaneous electrodes with a Grass stimulator $S 8800$, which gave supramaximal train-of-four (TOF) stimulations every $12 \mathrm{sec}$. The mechanical response (MMG) of both adductor pollicis muscles was measured by a force-displacement transducer (Grass FT-10) and recorded on a polygraph. Only patients with the same TOF ratio on each side were included in the study. During the recovery phase of neuromuscular blockade, simultaneous bilateral tetanic stimulation of $50 \mathrm{~Hz}$ for $5 \mathrm{sec}$ was given at different levels of relaxation. The minimal interval 
TABLE Tactile evaluation of the response to tetanic stimulation compared with mechanically measured response (MMG)

\begin{tabular}{lll}
\hline $\begin{array}{l}\text { Level of myorelaxation } \\
\text { measured by TOF ratio }\end{array}$ & $\begin{array}{l}\text { Tetanic fade confirmed } \\
\text { by } M G\end{array}$ & $\begin{array}{l}\text { Clinically detected } \\
\text { tetanic fade }\end{array}$ \\
\hline 0.10 & $32 / 32$ & $31 / 32(97 \%)$ \\
$0.20-0.30$ & $32 / 32$ & $25 / 32(78 \%)$ \\
$0.40-0.50$ & $26 / 32$ & $10 / 26(38 \%)$ \\
$0.60-0.70$ & $18 / 32$ & $4 / 18(22 \%)$ \\
\hline
\end{tabular}

between the repeated tetanic stimulations on the same patient was ten minutes. During tetanic stimulations, one of the patient's hands was freed in order to allow one observer to perform a tactile evaluation of the muscle response of the adductor pollicis. The observer had to say if the muscular contraction was sustained or not. That clinical tactile evaluation was then compared with the MMG response of the adductor pollicis on the other side, which measured the ratio of the amplitude of the response at the end of the $5 \mathrm{sec}$ tetanic stimulation to the initial maximal amplitude of the response at the beginning of the tetanic stimulation. A MMG tetanic response ratio greater than 0.95 was considered as a sustained tetanic contraction.

Four residents in their second year of training and four certified anaesthetists, all familiar with the use of nerve stimulators, formed the group of observers. Each carried out 16 evaluations which were randomly distributed in four series of four according to the TOF values, so that four measurements were done at TOF of 0.10 , four at TOF of $0.20-0.30$, four at TOF of $0.40-0.50$, and four at TOF of $0.60-0.70$. The observers were not aware of the distribution, and they did not know which levels of muscle relaxation were studied. A total of 128 tetanic responses was assessed.

The chi-square test was applied for statistical comparisons. A $P<0.05$ was considered significant.

\section{Results}

The Table shows the number of patients in which tetanic fade was found by MMG at the various levels of muscle relaxation studied, and the number in which the observers detected tetanic fade by clinical tactile evaluation.

As shown in Figure 1, residents were better than the certified anaesthesists in detecting tetanic fade. This difference was particularly marked at TOF values of $0.20-0.30$, where the residents detected tetanic fade in 100 per cent of the patients, while their senior counterparts felt the fade in only 56 per cent of patients $(P<0.001)$.

Figure 2 demonstrates the percentage of clinical tactile detection of tetanic fade in relation to MMG tetanic response ratio. Fade was clinically detected in all patients where the tetanic MMG response ratio was less than 0.30 .

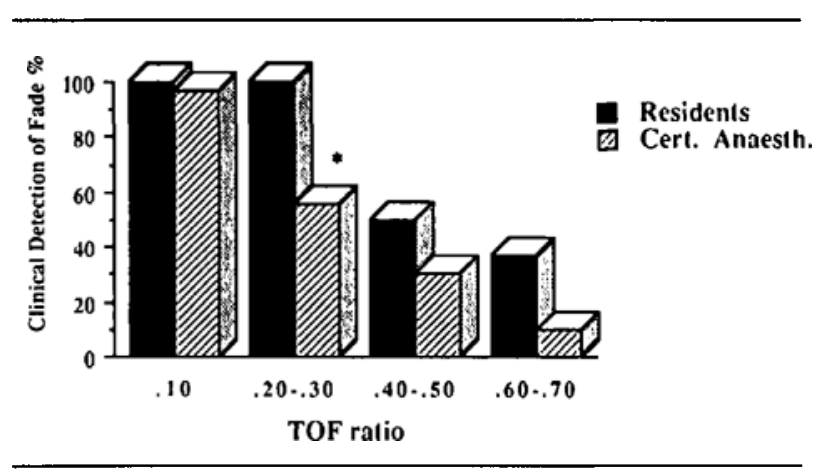

FIGURE I Clinically detected tetanic fade by residents and ansesthetists at differenı $T_{4} / T_{1}$ ratios. ${ }^{*} P<0.001$.

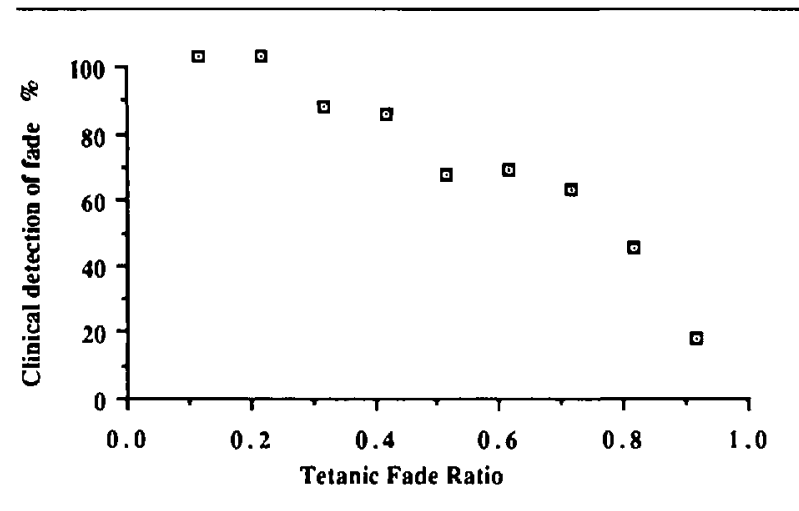

FIGURE 2 Percentage of clinical detection of fade at different tetanic fade ratios.

\section{Discussion}

Our results indicate that clinical tactile evaluation of the muscular response following a tetanic nerve stimulation ( $50 \mathrm{~Hz}$ for $5 \mathrm{sec}$ ) is not a very sensitive method of detecting residual neuromuscular blockade. The incapacity in detecting manually the fade of a tetanic stimulation in the present study is similar to the incapacity in detecting manually the fade of a TOF stimulation reported previously ${ }^{7}$ (Figure 3).

The residents performed better than their tutors in assessing the response to tetanic stimulation. We believe that these results are biased by the fact that the residents often observed their tutors making clinical assessment of tetanic responses in the present study. This probably gave the residents a chance to realize that the clinical evaluation of the tetanic response is often erroneous. Consequently, they concentrated better during their evaluations. Therefore, a certain learning process could give a higher sensitivity to this clinical test.

The only tetanic frequency chosen for this study was 50 $\mathrm{Hz}$ because it is known to develop the same tension as a 


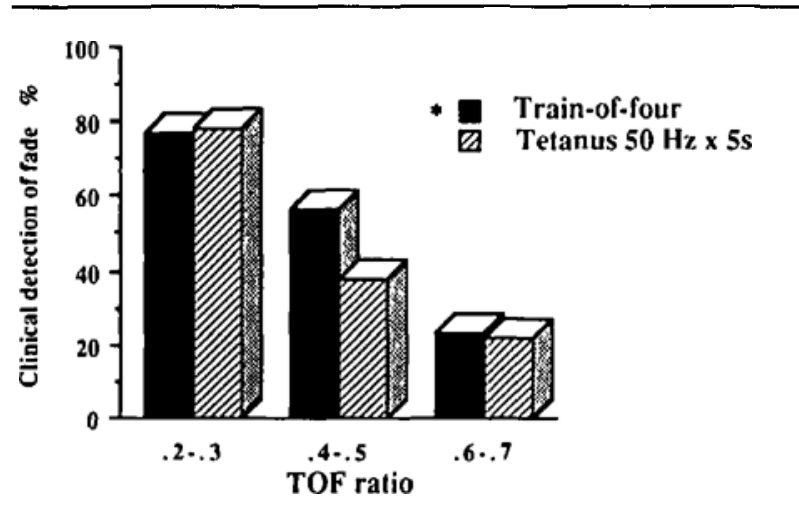

FIGURE 3 Clinical detection of fade by TOF and tetanic stimulation. *Values for TOF are reproduced with the permission of the authors (Ref. 7).

maximal voluntary effort, ${ }^{8}$ and because higher frequencies are avoided in our current practice of anaesthesia, since they may produce fade in the absence of neuromuscular blockade. ${ }^{9}$

Even in the presence of isoflurane which causes fade during high-frequencies stimulation, ${ }^{10}$ the patients presented a sustained tetanic response at $M M G$ in almost 20 per cent of the cases where TOF was as low as 0.40-0.50. The greater sensitivity of TOF fade compared with MMG tetanic fade to detect the residual effect of d-tubocurarine has previously been described, ${ }^{1,12}$ but no study has determined that tetanic response was recognised as being sustained at such low TOF values. The possibility that repeated tetanic stimulation improved neuromuscular transmission can be excluded as five of the six patients who presented a sustained tetanic response at TOF of 0.40-0.50 did so at their first tetanic stimulation.

At a TOF of $0.60-0.70$, the tetanic response was sustained in 14 cases out of 32 . These results are comparable with those found in a previous study where volatile agents were not used. ${ }^{12}$ It was found then that 18 of 28 patients had a sustained tetanic response at a TOF value of approximately 0.70 . One of the conclusions drawn from that study was that a TOF ratio of 0.70 or more correlated with a sustained tetanus at $50 \mathrm{~Hz}$ for 5 sec. Clinical criteria of adequate recovery were correlated to TOF ratio of $0.70,{ }^{13,14}$ and subsequently to sustained tetanus at $50 \mathrm{~Hz}$ for $5 \mathrm{sec} .^{12}$ However, it appears from our results that a sustained tetanic MMG response can be matched to a wide range of TOF values, varying from 0.50 to greater than 0.70 . This means that even if the anaesthetist could adequately detect a sustained tetanus by touch, he would then be confronted with the problem of not knowing the clinical meaning of his assessment.

Postoperative residual neuromuscular blockade is not a rare phenomenon. ${ }^{15-17} \mathrm{~A}$ recent study reemphasized the need for rigourous neuromuscular monitoring to avoid the potential danger of residual curarization. ${ }^{17}$ Knowing that the clinical interpretation of the muscular response after TOF and tetanic stimulations is unreliable in detecting subtle levels of muscle relaxation, we have to conclude that rigorous monitoring is not possible with the current neurostimulators usually utilized, which does not include a force displacement transducer with graphic recording.

A new pattern of stimulation, double-burst stimulation, has recently been described. ${ }^{18,19}$ Although superior to TOF in the manual evaluation of fade, this type of stimulation still does not not allow 100 per cent detection of residual curarization at TOF value of 0.50 to 0.70 . We believe that double-burst stimulation would be of clinical help only if the chosen frequencies of stimulation were those allowing a fade ratio of 0.30 (ratio of the amplitude of the second response on the amplitude of the first one) at TOF of $0.50-0.70$. Our assumption is based on the combined results of a previous study ${ }^{7}$ and ours, which showed that fade is clinically detected in almost 100 per cent of patients only when the TOF and the tetanic fade ratios are $<0.30$.

We conclude that the clinical tactile assessment of the response to tetanic stimulation $(50 \mathrm{~Hz}$ for $5 \mathrm{sec}$ ) is not a very accurate measure of fade and possible residual muscle relaxation. Its use should probably be restricted to the evaluation of intense neuromuscular blockade by post-tetanic count. ${ }^{20}$

\section{References}

1 Churchill-Davidson $H C$. A portable peripheral nervestimulator. Anesthesiology 1965; 26: 224-6.

2 Katz RL. A nerve stimulator for the continuous monitoring of muscle relaxant action. Anesthesiology 1965; 26: 832-3.

3 Walts $L F$, Levin N, Dillon JB. Assessment of recovery from curare. JAMA 1970; 213: 1894-6.

4 Viby-Mogensen J. Clinical assessment of neuromuscular transmission. Br J Anaesth 1982; 54: 209-23.

5 Jones RM. Neuromuscular transmission and its blockade. Anaesthesia 1985; 40: 964-76.

6 Walts $L F$. Evaluation of recovery from nondepolarizing neuromuscular block, using a digital neuromuscular transmission analyzer: preliminary report. Guest discussion. Anesth Analg 1973; 52: 744-5.

7 Viby-Mogensen J, Jensen NH, Engbaek J, Ording $H$, Skovgaard LT, Chraemmer-Jorgensen B. Tactile and visual evaluation of the response to train-of-four stimulation. Anesthesiology 1985; 63: 440-3.

8 Merton PA. Voluntary strength and fatigue. J Physiol 1954; 123: 553-64. 
9 Stanec A, Heyduk J, Stanec G, Orkin LR. Tetanic fade and post-tetanic tension in the absence of neuromuscular blocking agents in anesthetized man. Anesth Analg 1978; 57: 102-7.

10 Miller RD, Eger El II, Way WL, Stevens WC, Dolan $W M$. Comparative neuromuscular effects of forane and holathane alone and in combination with d-tubocurarine in man. Anesthesiology 1971; 35: 38-42.

11 Lee C, Barnes A, Katz RL. Neuromuscular sensitivity to tubocurarine. Br J Anaesth 1976; 48: 1045-51.

12 Ali HH, Savarese JJ, Lebowitz PW, Ramsey FM. Twitch, tetanus and train-of-four as indices of recovery from nondepolarizing neuromuscular blockade. Anesthesiology 1981; 54: 294-7.

13 Ali $H H$, Kitz RJ. Evaluation of recovery from nondepolarizing neuromuscular block, using a digital neuromuscular transmission analyzer: preliminary report. Anesth Analg 1973; 57: 740-5.

14 Ali HH, Wilson RS, Savarese JJ, Kitz RJ. The effect of tubocurarine on indirectly elicited train-of-four muscle response and respiratory measurements in humans. $\mathrm{Br} \mathrm{J}$ Anaesth 1975; 47: 570-4.

15 Viby-Mogensen J, Chraemmer-Jorgensen B, Ording $H$. Residual curarization in the recovery room. Anesthesiology 1979; 50: 539-41.

16 Beemer $G H$, Rozental $P$. Postoperative neuromuscular function. Anaesth Intensive Care 1986; 14: 41-5.

17 Bevan DR, Smith CE, Donati F. Postoperative neuromuscular blockade: a comparison between atracurium, vecuronium and pancuronium. Anesthesiology 1988; 69 : 272-6.

18 Engbaek J, Ostergaard D, Viby-Mogensen J. Doubleburst stimulation (DBS): a new pattern of nerve stimulation to identify residual neuromuscular block. $\mathrm{Br} J$ Anaesth 1989; 62: 274-8.

19 Drenck NR, Ueda N, Olsen NV et al. Manual evaluation of residual curarization using double burst stimulation: a comparison with train-of-four. Anesthesiology 1989; 70: 578-81.

20 Viby-Mogensen J, Howardy-Hansen P, ChraemmerJorgensen B. Ording H, Engbaek J. Nielsen A. Post tetanic count (PTC): a new method of evaluating an intense nondepolarizing neuromuscular blockade. Anesthesiology $1981 ; 55: 458-61$ 